\title{
Cash in Hand may wane Your Health: A Retrospective Cohort Study
}

\author{
${ }^{1}$ Prashant Rajput, ${ }^{2}$ Subha S Dany, ${ }^{3}$ Pradeep Tangade, ${ }^{4}$ Choubarga Naik, ${ }^{5}$ Manu Batra, ${ }^{6}$ Aasim F Shah
}

\begin{abstract}
Aim: To assess the effect of handling currency notes on the health of bank cashiers.

Materials and methods: Currency notes which were taken from 20 randomly selected nationalized banks of Moradabad, India, were subjected to microbiological profile. On a sample of 45 cashiers and 45 general staff of those banks, a retrospective cohort study was conducted. Absentees of both the cohorts were calculated from the attendance register and the reason behind taking each leave was asked, then the leaves taken due to sickness, such as common cold, throat infection, fever, stomach cramps, nausea/vomiting, diarrhea, skin infection, eye flue, urinary tract infection, were calculated separately. Calculations were done to get percentage of contamination of currency notes. Mean and standard deviation for each variable for the cohorts were calculated, and unpaired t-test was used for comparing between the cohorts. Statistical significance was set at $p \leq 0.05$.

Results: When the two groups were analyzed, more cashiers were found to be absent from their duties due to sickness as compared with the general staff, and the difference between the two is statistically significant $(p=0.039)$. On comparing between the two groups, a statistically significant difference was observed for the leaves taken due to throat infection and fever.

Conclusion: Because of their profession, cashiers are at high risk of developing communicable infections. So they need to be aware of their vulnerability to get infected and should be provided with proper knowledge to maintain their health while doing justice to their profession.
\end{abstract}

Keywords: Currency notes, Escherichia coli contamination, Microbiome, Public health.

${ }^{1}$ District Consultant, ${ }^{2}$ Senior Resident, ${ }^{3}$ Professor and Head ${ }^{4}$ Assistant Professor, ${ }^{5}$ Reader, ${ }^{6}$ Registrar

${ }^{1}$ National Tobacco Control Programme, Department of Health Government of Uttar Pradesh, Moradabad, Uttar Pradesh India

${ }^{2,4}$ Department of Dentistry, Veer Surendra Sai Institute of Medical Sciences and Research, Sambalpur, Odisha, India

${ }^{3}$ Department of Public Health Dentistry, Teerthanker Mahaveer Dental College \& Research Centre, Moradabad, Uttar Pradesh India

${ }^{5}$ Department of Public Health Dentistry, Maharaj Ganga Singh Dental College \& Research Centre, Sri Ganganagar, Rajasthan India

${ }^{6}$ Department of Public Health Dentistry, Government Dental College \& Hospital, Srinagar, Jammu and Kashmir, India

Corresponding Author: Subha S Dany, Senior Resident Department of Dentistry, Veer Surendra Sai Institute of Medical Sciences and Research, Sambalpur, Odisha, India, Phone: +918899477313, e-mail: dr.subhamdany@gmail.com
How to cite this article: Rajput P, Dany SS, Tangade P, Naik C, Batra M, Shah AF. Cash in Hand may wane Your Health: A Retrospective Cohort Study. J Oral Health Comm Dent 2017;11(3):51-54.

\section{Source of support: Nil}

Conflict of interest: None

\section{INTRODUCTION}

The environment plays an important role in transmission of microbial agents to humans, with many environmental materials serving as vehicles. Globally, the most frequently passed item from hand to hand is the currency note. A larger surface area is offered by paper currency notes as a breeding ground for pathogens. Microbes may persist on notes for longer periods, and thus they are more contaminated than coins. As the paper note becomes older, the chances of it getting more accumulated with microbes increase. ${ }^{1}$ During its passing, money can get contaminated and may thus play a role in the transmission of microorganisms to other people. For example, during counting of currency notes, microorganisms from the respiratory and gastrointestinal tract may contaminate the money. ${ }^{2}$ Sporadic food-borne illness cases are mostly due to simultaneous handling of paper currency and food. ${ }^{3}$ And especially in India where many people count money by applying saliva on their fingertips the chances of contamination of the currency notes are even higher. So, paper currency forms a specific risk to public health. Since communicable diseases can spread through contact with fomites, cashiers are the persons who come in contact with the money more frequently and are therefore, at higher risk of developing communicable diseases. In developing countries like India, there is scarce research on contamination of circulating currency notes, which contributes to the absence of public health policies regarding currency usage, handling, and circulation. So, keeping this in mind, the aim of our study was to assess the effect of handling currency notes on the health of bank cashiers.

\section{MATERIALS AND METHODS}

\section{Collection of Notes}

A total of 180 paper notes of 100,500 , and 1,000 denominations (60 each) were collected from 20 randomly selected nationalized bank cash counters of Moradabad city, 
Uttar Pradesh, India. The year of printing of these notes was matched. Sterile gloves were used for the collection of these notes which were placed in sterile containers.

\section{Bacteriological Analysis}

Standard techniques were used for isolation of various bacterial contaminants from the currency notes. ${ }^{4,5}$ Both sides of the currency notes were swabbed with a sterile, cotton-tipped swab moistened with saline. Blood agar and MacConkey agar were used for inoculation of the swabs, then according to standard protocol they were incubated aerobically at 35 to $37^{\circ} \mathrm{C}$ for 24 hours followed by bacterial growth examination. ${ }^{6}$ Bacterial isolation was done by assessing colony characteristics and Gram reaction, and by conducting catalase and coagulase tests; hemolysis, sugar fermentation, and other biochemical tests, including tests for indole production, citrate utilization, and urase activity; triple sugar iron agar tests (for glucose, sucrose, and lactose fermentation); gas and hydrogen sulfide production tests; and oxidase tests, according to Cheesbrough. ${ }^{6}$ Identification of bacteria was done, but they were not quantified.

\section{Parasitological Analysis}

For the isolation of enteric parasites standard concentration techniques were used. ${ }^{7,8}$ A very light foam material was used for making the swab, then $2 \times 2 \mathrm{~cm}$ size pieces were cut out, washed with detergent, and dipped in dilute solution of sodium hypochlorite for sterilization. The pieces of foam were then rinsed in water, air-dried, and rinsed in 70\% alcohol. They were oven-dried and stored in a well-covered container until used. Each piece of foam was moistened with formol-saline solution and used to swab both sides of the currency note. The swab was placed in a capped bottle containing $10 \mathrm{~mL}$ of formolsaline solution, and the bottle was shaken vigorously. Thereafter, the swab was pressed against the inner sides of the bottle with sterile forceps and removed. The solution was poured into a centrifuge tube and centrifuged at 2,000 g for 5 minutes. The supernatant was decanted, and a drop of the sediment was placed on a glass slide, covered with a glass coverslip, and examined microscopically for parasite ova. Standard guidelines (WHO, 2004) ${ }^{9}$ were used for identification of parasites. Parasites were identified but were not quantified.

\section{Identification of Fungi}

The growth of fungi on Sabaroud dextrose agar was examined critically after 1 week using prepared microscope slides. The prepared specimens were mounted on lactophenol cotton blue, and identification of the fungal species was performed with aid of binocular compound microscope $(40 \times)$ adopting the techniques used by Bruge. ${ }^{10}$ Then a retrospective cohort study was planned on bank cashiers of those 20 nationalized banks of Moradabad city, India. Study population consisted of all the cashiers aged 35 to 45 years. Out of these, 45 cashiers present on the scheduled day of investigation and who gave informed consent were recruited into the study. To form a comparison group, 45 other official bank staff members, aged 35 to 45 years, were selected. From their attendance register, absentees of both the cohorts were calculated for last 1 year, and the reason behind taking each leave was enquired. Then the leaves taken separately due to sickness, such as common cold, throat infection, fever, stomach cramps, nausea, vomiting, diarrhea, skin infection, eye flue, and urinary tract infection were calculated.

\section{Statistical Analysis}

Percentage (\%) of contamination of currency notes with bacteria, parasites, and fungi was calculated. For each variable of the cohorts, mean and standard deviation were calculated, and for comparing between the cohorts parametric unpaired t-test was used. Statistical significance was set at $\mathrm{p} \leq 0.05$.

\section{RESULT}

From the analysis of the 180 paper currency notes collected from 20 nationalized banks of Moradabad city, Uttar Pradesh, India, it was established that bacteria, protozoa, or fungi were present on $100 \%$ of the currency notes. Lower denominations were more contaminated with microbial load than higher denominations (Table 1). The total leaves taken by the cashiers $(1,437)$ were less than that taken by the general staff $(1,446)$. But the number of leaves taken due to sickness was more in the cashiers

Table 1: Bacterial, parasitical, and fungal analysis of currency notes

\begin{tabular}{llll}
\hline & $100(\%)$ & $500(\%)$ & $1,000(\%)$ \\
\hline Acid fast bacilli & 4.83 & 4.32 & 3.21 \\
E. coli & 15.08 & 13.54 & 11.90 \\
Staphylococci spp. & 23.79 & 21.92 & 18.57 \\
Staphylococcus aureus & 4.08 & 3.73 & 2.86 \\
Bacillus spp. & 23.77 & 22.02 & 19.08 \\
Streptococcus pyogenes & 9.10 & 8.44 & 6.32 \\
Pseudomonas spp. & 8.61 & 5.81 & 3.49 \\
Klebsiella spp. & 7.64 & 7.13 & 5.01 \\
Shigella dysenteriae & 13.71 & 11.35 & 9.11 \\
Protozoa, Ascaris lumbricoides, & 4.17 & $\mathrm{Nil}$ & $\mathrm{Nil}$ \\
Entamoeba histolytica & & & \\
Aspergillus spp. & 13.05 & 12.13 & 8.38 \\
Saccharomyces cerevisiae & 21.32 & 19.27 & 17.09 \\
\hline
\end{tabular}


Table 2: Comparison of the leaves taken by the cashiers and general staff

\begin{tabular}{|c|c|c|c|c|c|c|}
\hline & \multicolumn{2}{|c|}{ Cashier, $n=45$} & \multicolumn{2}{|c|}{ General staff, $n=45$} & \multirow[b]{2}{*}{$t$-value ${ }^{\#}$} & \multirow[b]{2}{*}{$p$-value } \\
\hline & Number of leaves & Mean $\pm S D$ & Number of leaves & Mean $\pm S D$ & & \\
\hline Total leaves due to sickness & 353 & $7.84 \pm 3.86$ & 277 & $6.15 \pm 3.78$ & 2.094 & $0.039^{*}$ \\
\hline Common cold & 77 & $1.71 \pm 1.42$ & 62 & $1.37 \pm 1.31$ & 1.152 & 0.253 \\
\hline Throat infection & 102 & $2.26 \pm 1.42$ & 77 & $1.71 \pm 1.22$ & 1.992 & $0.049^{*}$ \\
\hline Fever & 73 & $1.62 \pm 1.15$ & 52 & $1.15 \pm 0.99$ & 2.051 & $0.043^{*}$ \\
\hline Stomach cramps & 50 & $1.11 \pm 1.22$ & 45 & $1 \pm 1.15$ & 0.443 & 0.659 \\
\hline Nausea/vomiting & 33 & $0.73 \pm 0.89$ & 25 & $0.55 \pm 0.84$ & 0.974 & 0.333 \\
\hline Diarrhea & 9 & $0.2 \pm 0.54$ & 7 & $0.15 \pm 0.47$ & 0.411 & 0.682 \\
\hline Skin infection & 4 & $0.09 \pm 0.35$ & 5 & $0.11 \pm 0.38$ & 0.284 & 0.777 \\
\hline Eye flu & 1 & $0.02 \pm 0.14$ & 2 & $0.04 \pm 0.20$ & 0.582 & 0.562 \\
\hline Urinary tract infection & 4 & $0.09 \pm 0.35$ & 2 & $0.04 \pm 0.20$ & 0.145 & 0.474 \\
\hline Total leaves & 1,437 & $31.93 \pm 13.09$ & 1,446 & $32.13 \pm 12.90$ & 0.765 & 0.942 \\
\hline
\end{tabular}

\#Unpaired student's t-test; ${ }^{*} \mathrm{p} \leq 0.05$ is statistically significant; SD: Standard deviation

(353) as compared with other staff (277). This difference was also found to be statistically significant with $\mathrm{p}=$ 0.039 (Table 2).

\section{DISCUSSION}

In our study, $100 \%$ of the currency notes were contaminated. Several other studies have also reported bacterial contamination from $60 \%$ to as much as $100 \%$ on tested paper currencies. All (100\%) of the currency notes were found to be contaminated with bacteria in a study conducted on Indian rupee, Bangladeshi Taka, and Iraqi and Ghanaian currency notes. ${ }^{11}$ About $88 \%$ of Saudi one Riyal paper note, $96.25 \%$ of Palestine bank note, $69 \%$ of Mexico currency notes, 91.1\% Colombian bills, and $90 \%$ of South African bank notes were contaminated with pathogenic or potentially pathogenic bacteria with mixed bacterial growth. ${ }^{11}$ Several mechanisms have been suggested to explain the contamination: Improper hand washing after using the toilet, counting paper notes using saliva, coughing and sneezing on hands then exchanging money, and placement or storage of paper notes on dirty surfaces. In our study, 100\% of the currency notes were contaminated with one or other form of microbes and these results were similar to the study by Uneke, ${ }^{12}$ who isolated parasites from the notes including Ascaris lumbricoides (8.0\%). Besides, Streptococcus species (21.6\%), Staphylococcus species (12.8\%), Escherichia coli (13.2\%), and Bacillus species (5.6\%) bacteria were also isolated from currency notes. ${ }^{12}$ Smaller denomination currency notes were found to be highly contaminated than higher denomination notes, probably because the smaller unit notes are most repeatedly handled in minor, day-to-day monetary dealings. Old, ragged, and filthy notes were more contaminated than new notes and thus support the finding that damaged or soiled notes, especially those held together, with bits of sticky tape are particularly dangerous. ${ }^{13}$ In the present study, the cashiers had taken more leaves as compared with the general staff, which was calculated from the total leaves taken because of sickness for both cohorts. The leaves taken due to throat infection and fever were also more in cashiers with a statistically significant difference. The reason behind this may be because they come in contact with the currency notes more frequently and most of the currency notes are contaminated by streptococcal species, which is one of the causes for throat infection. ${ }^{14}$ Significant difference in leaves taken due to fever may be because fever can be caused due to infection by any of the microbes, as fever is actually the body's natural way of defending itself from invaders like viruses and bacteria, because many of them cannot survive in the body due to the high temperature caused by it. Presence of E. coli, Shigella, Staphylococcus aureus, and other parasites may be the reason behind the leaves taken due to diarrhea, nausea/vomiting, and stomach cramps by cashiers and other staff as these are the species responsible for these conditions. ${ }^{15}$ Although cashiers had taken more leaves due to these causes, the difference was not statistically significant because the level of contamination of higher denomination notes which the cashiers usually handle is less than that of the lower denomination notes. According to regional sophisticated instrumentation center research, Indian currency notes are contaminated with various other dangerous bacteria which can cause diseases like tuberculosis, meningitis, tonsillitis, peptic ulcer, throat infection, genital tract, hepatitis, etc. ${ }^{16}$ Studies conducted on ordinary paper showed differences in length of survival depending on environmental room conditions, but were stable on paper for up to 72 hours and still cultivable after 7 days. ${ }^{17}$ On coins, some Gram-negative bacteria can remain as long as 11 days, and influenza virus can survive on currency notes for about 3 to 17 days. ${ }^{1}$ In India, the paper used for making currency is a special blend of cotton, linen, and other textile fiber that forms a more suitable substrate 
for the growth of bacteria. However, bank notes' material of many countries has more recently been replaced from paper to plastic polymer substrates. ${ }^{18}$ Although the primary purpose for the use of this plastic polymers substrate was to enhance security, it has been proven that this material provides other advantages, i.e., it has a higher tear resistance than paper, it is more resistant to folding and soiling, it is nonporous, and it does not absorb water or sweat. Given these characteristics, polymer bank notes may be cleaner than paper currency. ${ }^{18,19}$ Studies have shown that polymer-based bank notes often have a relatively low bacterial count compared with the cottonbased paper bank notes.

\section{CONCLUSION}

This study has shown that currency notes in circulation in Moradabad city are contaminated with potential pathogens, and those users and handlers of the notes are the sources of contamination. Although there is no direct evidence that presence of microorganisms on currency results in sickness, still the finding of our study gives an indication toward it. The general awareness about the possibility of acquiring infection while applying saliva on fingers for counting currency notes and practicing good personal hygiene should be created. The banks should be suggested to regularly disinfect currency notes by exposing them to ultraviolet rays or fumigation.

\section{REFERENCES}

1. El-Dars F, Hassan WM. A preliminary bacterial study of Egyptian paper money. Int J Environ Health Res 2005 Jun;15(3): 235-240.

2. Gedik H, Voss TA, Voss A. Money and transmission of bacteria. Antimicrob Resist Infect Control 2013 Aug;2:22.

3. Michaels B. Handling money and serving ready-to-eat food. Food Serv Tech 2002 Mar;2:1-3.
4. Gilchrist, MJR. Microbiological culturing of environmental and medical device surfaces. In: Eisenberg $\mathrm{H}$, editor. Clinical microbiology procedures handbook. Washington, DC: American Society for Microbiology; 1993. p. 11.10.4.

5. Singh DV, Thakur K, Goel A. Microbiological surveillance of currency. Indian J Med Microbiol 2002;20(1):53.

6. Cheesbrough, M. District laboratory practice in tropical countries, part 2. Cambridge: Cambridge University Press; 2000.

7. Cheesbrough, M. District laboratory practice in tropical countries, part 1. Cambridge: Cambridge University Press; 1998.

8. World Health Organization (WHO). Manual of basic techniques for a health laboratory, 2nd ed. Geneva: WHO; 2003.

9. World Health Organization (WHO). Bench aids for the diagnosis of intestinal parasites [CD-ROM]. Geneva: WHO; 2004.

10. Bruge HP. Comparative merits of eight popular media in aerometric studies of fungi. Allergy Clin Immunol. 1977 Sep;60:199-2003.

11. Agersew A. Microbial contamination of currency notes and coins in circulation: a potential public health hazard. Biomed Biotechnol 2014;2(3):46-53.

12. Uneke CJ. Potential for parasite and bacteria transmission by paper currency in Nigeria. J Environ Health 2007 May;69(9):54-60.

13. Siddique S. Dirty money: You're carrying more than cash in your wallet. Manila-Philippine Headline News Online. Reported by Vanzi SJ, 2003.

14. Cunningham MW. Pathogenesis of group A streptococcal infections. Clin Microbial Rev 2000 Jul;13(3):470-511.

15. Oo KN, Win PP, Han AM, Aye T. Contamination of currency notes with enteric bacterial pathogens. J Diarrhoeal Dis Res 1989 Sep-Dec;7(3-4):92-94.

16. Dirty contaminated money: Diseases spread through money (Currency notes). Regional sophisticated instrumentation Centre research. Cited on February 8, 2014.

17. Hobner N-O, Hobner C, Kramer A, Assadian O. Survival of bacterial pathogens on paper and bacterial retrieval from paper to hands: preliminary results. Am J Nurs 2011 Dec;111(12):30-34.

18. Explaining currency: New Zealand's bank notes and coins. Wellington: Reserve Bank of New Zealand; 2000. pp. 1-19.

19. Ahlers C, Martin M, Olsen B, O'Neil P, Sanchez M. How green is our green? A sustainability assessment of U.S. and Australian currency. ENVS 195 Sustainability Science 2010. 